Electrohydraulic lithotripsy of intrahepatic stones during choledochoscopy. Surgery 1987;102:852-6.

10 Liguory CL, Bonnel D, Canard JM, Cornud F, Dumont JL. Intracorporeal electrohydraulic shock wave lithotripsy of common bile duct stones: preliminary results in 7 cases. Endoscopy 1987;19:237-40.

11 Ebbs RR, Beckley DE, Hammonds JC, Tensdale C. Percutaneous electrohydraulic lithotripsy of retained bile duct calculus. Br Med f 1986;292:94.

12 Ikeda S, Yoshimoto H, Tanaka M, Matsumoto S, Itoh H. Cholangiography of intrahepatic bile ducts in hepatolithiasis by endoscopic placement of an indwelling balloon catheter. Gastrointest Endosc 1985;31:181-7.

13 Schneider MU, Matek W, Bauer R, Domschke W. Mechanical lithotripsy of bile duct stones in 209 patients - effect of technical advances. Endoscopy 1988;20:248-53.

14 Ell Ch, Lux G, Hochberger J, Muller D, Demling L. Laser lithotripsy of common bile duct stones. Gut 1988;29:746-51.

15 Kozarek RA, Low DE, Ball TJ. Tunable dye laser lithotripsy: in vitro studies and in vivo treatment of choledocholithiasis. Gastrointest Endosc 1988;34: $418-20$.

16 Leung JWC, Chung SCS, Mok SD, Li AKC. Endoscopic removal of large common bile duct stones in recurrent pyogenic cholangitis. Gastrointest Endosc 1988;34:238-41.

17 Sievert CE, Silvis SE. Evaluation of electrohydraulic lithotripsy on human gall stones. Am f Gastroenterol 1985;80:854.

18 Silvis SE, Siegel JE, Hughes R, Katon RM, Sievert CE, Sivak MV. Use of electrohydraulic lithotripsy to fracture common bile duct stones. Gastrointest Endosc 1986;32:155-6.

19 Nakajima M, Akasaka Y, Yamaguchi K, Fujimoto S, Kawai K. Direc endoscopic visualisation of the bile and pancreatic duct system by peroral cholangiopancreatoscopy (PCPS). Gastrointest Endosc 1978;24:141-4.

(Accepted 19 fune 1989)

\title{
Non-admission or non-invitation? A case-control study of failed admissions
}

\author{
Stephen Frankel, Alexandra Farrow, Robert West
}

\section{Abstract \\ Objective-To examine the causes of non-admis- sion to hospital.}

Design-Validation of published rates of nonadmission by examination of medical records, followed by a case-control study of non-attenders (cases) and attenders (controls).

Setting-General hospital.

Subjects-246 Patients (cases in the case-control study) booked for admissions in four specialties (general surgery, gynaecology, otorhinolaryngology, and trauma and orthopaedics) during April, May, and June 1987 who were not admitted for reasons that seemed to be attributable to the patients. Controls comprised 167 patients admitted to the same specialty on the same day.

Results - The validation of administrative records indicated that it is unusual for patients to fail to present for admission without advising the hospital beforehand; this occurred in only 1-3\% of all bookings. Information on the circumstances of nonadmission and clinical and personal details were collected by means of a six page questionnaire completed by the patients. The case-control study showed that those not admitted were younger and had been on the waiting list longer. Otherwise only small differences were found in the social and clinical characteristics.

Conclusions-Despite a common tendency to blame patients for non-admission, factors due to patients are fairly unimportant.

Department of Epidemiology and Community Medicine, University of Wales College of Medicine, Cardiff CF4 4XN

Stephen Frankel, DM, senior lecturer

Alexandra Farrow, MSC, research fellow

Robert West, PHD, reader

Correspondence to: Dr Frankel, Health Care Evolution Unit, Department of Epidemiology and Community Medicine, Canynge Hall,

Bristol BS8 2PR.

BrMed f 1989;299:598-600

\section{Introduction}

Considerable pressure exists on facilities for inpatients, and waiting lists are one expression of this.' When patients booked for admission fail to present themselves the task of reducing waiting lists is made more difficult. The perception is widespread that nonadmission of this sort is a serious problem. One inquiry suggested that between $10 \%$ and $12 \%$ of booked inpatients fail to present themselves, ${ }^{2}$ an estimate that led to a parliamentary question suggesting systematic reviews of waiting lists. ${ }^{3}$ The launch of a Scottish initiative to reduce waiting times in March 1988 included comments criticising "patients who failed to turn up for scheduled operations for adding to the problems." Resentment was expressed over "this waste of financial resources," and there followed an "appeal to patients to let hospitals know in advance if they cannot turn up." 4 The study reported here arose when an apparent rate of non-admission of $28 \%$ was reported in one health authority.
The empty beds and unused theatre time that follow failed admissions clearly represent an inefficient use of resources. Accounts of non-admission tend to accept as self evident the view that resources are being wasted and that non-admission is essentially a problem of compliance. In an earlier paper we questioned similar assumptions about non-attendance of outpatients. ${ }^{5}$ In this paper we examine explanations for the reported number of failed admissions.

\section{Subjects and methods}

An important preliminary to the investigation was the validation of the summary of rates of nonadmission derived from routine sources. We examined record sheets for admissions from 1 April to 30 June 1987 and obtained the total number of patients actually admitted in the four specialties of general surgery, otorhinolaryngology, gynaecology, and trauma and orthopaedics. These specialties were selected because of their throughput and the size of their waiting lists. When patients were identified on the record sheets as not having been admitted as planned one of several general explanations for non-admission was entered beside the name. These allowed a broad distinction to be drawn between factors due to the hospital and those due to the patients. Hospital factors comprised cancellation of the admission when no bed or theatre session was available. Patient factors were when patients cancelled because of other engagements or absence or because they were no longer seeking admission; for administrative purposes these were subdivided into whether sufficient notice was given to permit the booking of an alternative patient. Another group of non-admissions identified from the record sheets was those of patients who had already been admitted. The potential non-admission of such patients could reasonably have been known to the medical records department, and these cases were therefore classed under hospital factors.

After examining the routine records we undertook a questionnaire study incorporating a case-control design. The total final sample of patients was 413: 246 patients not admitted (cases) and 167 admitted (controls). We classed the non-admitted patients as all those identified on the record sheets from 1 April to 30 June 1987 whose failed admissions seemed to have been attributable to the patient rather than the hospital. Admissions were selected from the same specialty on the same booking sheet and when possible under the same consultant. We developed a six page self completion questionnaire to ask whether patients had presented on the day booked and, if they had not, what 
were their reasons for not coming. The questionnaire also inquired about factors such as duration of illness, degree of incapacity, difficulty in arranging time off work, and availability of someone to care for children or elderly dependants. Questionnaires were posted in September 1987. Events in July and August were not studied as summer holidays would make the period unrepresentative.

\section{Results}

REASONS FOR NON-ADMISSION

In the three months there were 2242 bookings, which resulted in 1625 admissions. Table I shows the outcome of these booked admissions. The overall nonadmission rate was 617 out of $2242(28 \%) ; 270(12 \%)$ bookings, however, failed for reasons clearly attributable to hospital factors: 208 bookings had been cancelled because of a lack of beds or theatres and for 62 bookings the patients had already been admitted. A

TABLE I-Categories of failed admission according to record sheets

\begin{tabular}{lc}
\hline Outcome of booked admission & $\begin{array}{c}\text { No of } \\
\text { patients }\end{array}$ \\
\hline Admitted on date booked & 1625 \\
Not admitted: & \\
Hospital factors: & 208 \\
$\quad$ Cancelled (no theatre or no beds) & 62 \\
Already admitted & 243 \\
Patient factors: & 3 \\
$\quad$ Permitting alternative booking & 101 \\
$\quad$ Dead & 2242 \\
$\quad$ Not permitting alternative booking &
\end{tabular}

total of $347(16 \%)$ bookings failed because of factors that might reasonably be attributed to patients, though on over two thirds of these occasions patients had given sufficient notice for an alternative booking to be made successfully. These 347 failed admissions were for 246 patients, showing that the same patient may experience more than one failed admission. Examination of the admission booking sheets showed that 101 bookings failed with no record of explanation or notification by the patient. The results of the questionnaire study permitted further examination of this group. These 101 unsuccessful admissions recorded on the booking sheets were for 80 patients. Questionnaires seeking explanations for these failures were returned by 42 patients. Eleven patients had been misclassified as non-admissions. Their admissions were subsequently validated from medical records. Eighteen patients reported that they had notified the hospital of their inability to present for admission; this was two thirds of the 27 patients who had potentially been able to notify the hospital. From reasons given on the booking sheets and from replies to the questionnaire it therefore seemed that non-admission without prior notification to the hospital occurred in only $1-3 \%$ of all booked admissions.

\section{CASE-CONTROL STUDY}

After two postings 260 questionnaires suitable for analysis were received from 413 patients selected. The response rates were $137 / 246(56 \%)$ for non-admitted patients and $123 / 167(74 \%)$ for admitted patients. The sex and age of the responders and non-responders were not significantly different, though there was a tendency for non-responders to be younger than responders (table II). Non-admitted patients were significantly younger than admitted patients both in the eligible sample $\left(\chi^{2}=32 \cdot 84, \mathrm{df}=5, \mathrm{p}<0.001\right)$ and among responders $\left(\chi^{2}=22 \cdot 10, \quad \mathrm{df}=5, \mathrm{p}<0 \cdot 001\right)$. Nonadmitted and admitted patients, however, did not
TABLE II-Age and sex of patients admitted and not admitted by responders to questionnaire and eligible sample. Figures are numbers (percentages)

\begin{tabular}{|c|c|c|c|c|}
\hline & \multicolumn{2}{|c|}{ Responders } & \multicolumn{2}{|c|}{ Eligible sample } \\
\hline & $\begin{array}{l}\text { Not admitted } \\
\quad(n=137)\end{array}$ & $\begin{array}{c}\text { Admitted } \\
(\mathrm{n}=123)\end{array}$ & $\begin{array}{l}\text { Not admitted } \\
\quad(n=246)\end{array}$ & $\begin{array}{l}\text { Admitted } \\
(\mathrm{n}=167)\end{array}$ \\
\hline \multicolumn{5}{|l|}{ Sex: } \\
\hline Male & $44(32)$ & $42(34)$ & $88(36)$ & $55(33)$ \\
\hline Female & $93(68)$ & $81(66)$ & $158(64)$ & $112(67)$ \\
\hline \multicolumn{5}{|l|}{ Age (years): } \\
\hline$<25$ & $17(12)$ & $19(15)$ & $41(17)$ & $30(18)$ \\
\hline 25 & $40(29)$ & $16(13)$ & $68(28)$ & $21(13)$ \\
\hline $35-$ & $31(23)$ & $14(11)$ & $58(24)$ & $20(12)$ \\
\hline $45-$ & $16(12)$ & $28(23)$ & $30(12)$ & $38(23)$ \\
\hline $55-$ & $15(11)$ & $17(14)$ & $20(8)$ & $23(14)$ \\
\hline$\geqslant 65$ & $18(13)$ & $29(24)$ & $29(12)$ & $35(21)$ \\
\hline
\end{tabular}

differ in their sex or their social characteristics of marital and employment state.

Table III shows the diagnoses for admission for all patients. Some reasons seemed to be associated with non-admission, particularly varicose veins and sterilisations, and others seemed to be associated with admission, particularly hip replacements and gynaecological investigations. These differences, however, were not significant. There was a slight trend for those not admitted to report less restriction of normal activities as a consequence of their complaints than those admitted, but this difference was not significant. Those not admitted were more likely to admit to worries about the admission (44 (32\%) compared with $\left.22(18 \%), \chi^{2}=7 \cdot 96, \mathrm{df}=1, \mathrm{p}<0.01\right)$.

TABLE III-Diagnoses for admission for patients not admitted and admitted

\begin{tabular}{lcc}
\hline Diagnosis for admission & Not admitted & Admitted \\
\hline Varicose veins & 14 & 6 \\
Hernia & 5 & 10 \\
Other general surgery & 14 & 13 \\
Sterilisation & 13 & 4 \\
Gynaecological investigations & 18 & 25 \\
Otorhinolaryngological operations & 34 & 26 \\
Hip replacement & 3 & 9 \\
Other orthopaedic operations & 7 & 4 \\
Others & 29 & 26 \\
\hline Total & 137 & 123 \\
\hline
\end{tabular}

Patients were also asked what particular procedures they had expected to undergo during the planned admission. The main difference between those admitted and those not admitted was the larger number of those admitted who understood their admission to be for tests (eight of those not admitted compared with 25 of those admitted, $\chi^{2}=11 \cdot 17, \mathrm{df}=3, \mathrm{p}<0 \cdot 02$ ). The uncertainty raised by the need for investigation may increase the determination of patients to attend. Those who were not admitted were more likely to have waited longer. Three of those not admitted had waited less than one month compared with 12 of those admitted $\left(\chi^{2}=9 \cdot 55, \mathrm{df}=4, \mathrm{p}<0.05\right)$.

\section{Discussion}

High non-admission rates, such as the $28 \%$ reported in the study district, are often held to imply a troublesome amount of indifference to clinical and administrative concerns on the part of patients. Our study, however, showed that little of the overall problem of non-admission could be attributed to indifference on the part of patients. The problem is not patients causing empty beds or underused theatre sessions so much as unavailable beds or theatre sessions preventing patients from being admitted. One third of the failed admissions had arisen because of cancellations by the hospital, and a further tenth could 
reasonably have been predicted by the hospital because the patient had been admitted already. Over one third of patients notified the hospital in sufficient time for an alternative patient to be booked. Thus the proportion of bookings for which there was no record of patients having given notice of not presenting was only $5 \%$.

The results of the questionnaire study indicated that even this is a considerable overestimate. Though nonadmission is clearly not the problem that a supposed rate of $28 \%$ suggested, any non-admission should be of concern to health service management. The explanation of these failed admissions cannot be fully understood from routine sources of data as little is recorded in medical records about true non-admissions. The reasons for failed admissions can be studied adequately only by approaching the patients personally. There are obvious difficulties, however, in studying defaulters as they may be as unlikely to answer questionnaires as they are unwilling or unable to answer invitations to hospital. In the questionnaire study the sample of those not admitted was selected expressly to represent the more problematic group of non-admissions that could, from the analysis of medical records, be attributed to the patients. Nevertheless, respondents' reasons indicated mostly that they had been told not to attend by the hospital or that they had advised the hospital more than a week before their admission that they had been admitted previously. While it is important to consider some self justification here on the part of responders and the effect of bias associated with a low response rate, claims of admission were validated from medical records. Accordingly, despite the potential for bias in responses from a problematic group of nonadmissions and the possibility of self justification because of this, we suggest that the true non-admissions comprise only a small proportion, some $1-3 \%$, of all bookings.

Some differences were found between those who were admitted and those who were not. Patients who were not admitted were younger, slightly more likely to have minor complaints, and less worried about their conditions. Probably the tendency for responders to be older than non-responders resulted in an underestimate of these differences. That those who were not admitted had been on the waiting list longer than those who were admitted accords with the well known problems of long waiting lists. Probably the relation between long waiting times and non-admission would have been more distinct if there had not been a purge on waiting lists just before this study.

The more striking finding from returned questionnaires was the lack of difference between patients not admitted and those admitted in sex, employment, and marital state. This is of course what we would expect if the main explanations for non-admission are to be found in the hospital's admission procedures rather than in the circumstances or attitudes of patients. These findings are therefore consistent with the conclusions of the examination of the booking sheets.

We undertook this study because non-attendance for booked admission was seen as a problem for the health service. Our findings indicate that non-admission is rarely attributable to patients simply failing to present themselves. Cancellation of admissions by the hospital was the single most important reason for non-admission. There was little evidence of clinical resources being wasted because of non-admission. Considerable though unmeasurable costs of current policies are borne by the patients in the form of inconvenience and anxiety. We do not conclude that the detailed administrative arrangements for admission are flawed in themselves. The pursuit of efficiency implies minimising unused facilities. This goal may conflict with the aim of minimising the inconvenience of individual patients. Our study indicates one implication of favouring efficiency.

Some interesting parallels exist between professional responses to these issues and professional interpretations of ineffective health promotion or screening campaigns. In both instances there is a tendency to seek external explanations for failure in preference to reviewing the programme itself. This tendency has been dubbed "victim blaming" in relation to preventive programmes. ${ }^{6}$ Our studies of non-attendance of outpatients $s^{5}$ and non-admission suggest that this same tendency may be discerned in some interpretations of inadequacies of provision of outpatient assessment or inpatient treatment. External explanations for imperfect services are not threatening to those who work within those services. In contrast, an internal review implicating inadequate procedures for appointments, outpatient departments overloaded by unnecessary reattendances, and deficiencies in the scheduling of admissions may be less welcome. External problems arising from limited resources and the capriciousness of patients certainly exist. Our findings in this study and the study of non-attendance of outpatients, ${ }^{5}$ however, suggest that concern with those factors attributable to patients outside the immediate influence of management require less attention than those inadequacies in the management of inpatient and outpatient bookings. 1 Frankel SJ. The natural history of waiting lists-some wider explanations for an
unnecessary problem. Health Trends 1989;21:54-6.

2 Davies $P$. Why don't patients turn up? Health and Social Service Journal 1984 July 26:886-7.

3 Mawhinney B. Parliamentary written question. House of Commons Official Report (Hansard) 1984 June 26;61:col 410.

4 Christie B. Forsyth's blitz on waiting lists. Scotsman 1988 March 30:6 (cols 1-3).

5 Frankel SJ, West RR, Farrow A. Non-attendance or non-invitation? A casecontrol study of failed outpatient appointments. Br Med f 1989;298:1343-5. 6 Crawford R. You are dangerous to your health: the ideology and politics of victim blaming. Int I Health Ser 1977; 7:663-80.

(Accepted 26 fune 1989)

\section{Correction}

Local hyperthërmia benefits natural and experimental common colds

Three authors' errors occurred in this paper by Dr David Tyrel and others (13 May, p 1280-3). The abstract should state that volunteers showed an $18 \%$ reduction in symptoms and not a $43 \%$

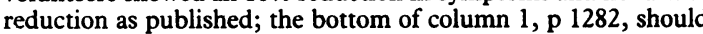
read $29 v 24$ and not $14 v 24$; and the top of column 2, p 1282, should read $18 \%$ and $21 \%$ and not $43 \%$ and $21 \%$. 